\title{
Preparation of GO/PAM Continuous Adsorption Medium and its Dynamic Adsorption Properties for Methylene Blue
}

\author{
Dagang $\mathrm{LI}^{1,2, *}$, Zhiwen WANG ${ }^{2}$ \\ ( ${ }^{1 .}$ Department of Materials and Chemical Engineering of Liming Vocational University, Quanzhou 362000, Fujian, China. ${ }^{2 .}$ Applied \\ Technology Engineering Center of Fujian Provincial Higher Education for Practical Chemical Material, Quanzhou 362000, Fujian, China)
}

\begin{abstract}
A continuous and structured porous adsorbent named GO/PAM was synthesised by one-step copolymerization of graphene oxide (GO) and acrylamide (AM) in amorphous region initiated by redox agent consisting of hydrogen peroxide $\left(\mathrm{H}_{2} \mathrm{O}_{2}\right)$ and ascorbic acid $(\mathrm{VC})$ at $-20^{\circ} \mathrm{C}$. The dynamic adsorption characteristics of methylene blue (MB) in GO/PAM structured adsorption medium were investigated. With the introduction of $\mathrm{GO}$ which rich in $-\mathrm{OH}$ and $-\mathrm{COOH}$ groups, the adsorption capacities were 178.65 $\mathrm{mg} / \mathrm{g} 201.58 \mathrm{mg} / \mathrm{g}$. Structured continuous adsorption medium was prepared by one-step polymerization of crystallization, in order to replace traditional bulk resin and ion exchange resin in the treatment of printing and dyeing wastewater.
\end{abstract}

\section{Introduction}

Textile printing and dyeing industrial wastewater's largescale and high-efficiency treatment is an important issue to be solved in the field of environmental protection ${ }^{[1-2]}$. In many studies, adsorption method has been widely used because of its strong selectivity and simple posttreatment, such as the use of adsorption $\operatorname{resin}^{[3]}$, ion exchange resin ${ }^{[4-5]}$, adsorption membrane material ${ }^{[6-7]}$ to be adsorbents and so on. In this paper, Graphene oxide (GO) rich in $-\mathrm{COOH},-\mathrm{OH},-\mathrm{O}-$ and other groups, was selected as functional raw material to form aqueous solution polymerization system with acrylamide (AM) to prepare the GO/PAM structured adsorption medium. At the same time, the dynamic adsorption characteristics of methylene blue (MB) dye on GO/PAM structured adsorption medium were explored in order to achieve large-scale adsorption treatment of printing and dyeing wastewater containing MB.

\section{Experimental}

\subsection{Materials}

Acrylamide (AM, 99.9\%), Methylene blue (MB, 99\%) and hydrogen peroxide(H2O2,30\%) were supplied by Sinopharm Chemical Reagent Co., Ltd (Shanghai, China). N, N'-methylene-bis-acrylamide (MBA, 99\%) and ascorbic acid(VC, 99.9\%) were bought from Xilong Chemical Co., Ltd (Shantou, China). Graphene oxide (GO, 1 7 layers) was purchased from Suzhou hengqiu technology graphene Co., Ltd (Suzhou, China). Ethanol $(95 \%)$ and other chemicals were of analytical grade obtained from local sources.

\subsection{Preparation of GO/PAM structured adsorption medium}

GO solution and AM solution were prepared into monomer aqueous solution, and then crosslinker MBA and oxidant $\mathrm{H} 2 \mathrm{O} 2$ were added into monomer aqueous solution to form polymerization system (the total mass fraction of $\mathrm{GO}$ and monomer $\mathrm{AM}(\mathrm{w}(\mathrm{AM}+\mathrm{GO})=3 \%$ $\sim 7 \%, \mathrm{~m}(\mathrm{GO}): \mathrm{m}(\mathrm{AM}): 0 \sim 0.25, \mathrm{w}(\mathrm{MBA})=0.9 \% \sim$ $1.7 \%$ ) . After being mixed evenly, they were put into refrigeration equipment (SC-15, provided by Ningbo Tianheng instrument factory, China) to reduce temperature to $-5^{\circ} \mathrm{C}$ for prefreezing, then quickly add the reducing agent $\mathrm{VC}$ dissolved in deionized water (the total mass fraction of $\mathrm{H} 2 \mathrm{O} 2$ and $\mathrm{VC}$ in the system were $\mathrm{w}(\mathrm{i})=0.1 \%$, where $\mathrm{m}(\mathrm{VC}): \mathrm{m}(\mathrm{H} 2 \mathrm{O} 2)=0.6$ ), quickly pour it into a chromatographic column ( size: diameter(D) $\times$ diameter $(\mathrm{L})=18 \mathrm{~mm} \times 200 \mathrm{~mm})$ at prefreezing temperature, and put it in the lowtemperature freezing equipment. Controlled the temperature of the refrigeration equipment to drop to $20{ }^{\circ} \mathrm{C}$ in $30 \mathrm{~min}$.

\subsection{Dynamic adsorption experimental}

(1) Dynamic adsorption of MB on GO/PAM

The medium was installed in the device with temperature control system, and the operation flow is shown in Fig.1. The concentration of MB in the effluent was detected every 10 minutes to determine the breakthrough curves under different adsorption conditions. In this work, the time of reaching the exit concentration $c_{\text {eff }}=0.1 c_{\text {in }}$ in all breakthrough curves was

${ }^{*}$ Corresponding author. Dagang LI. E-mail address: 278843035@qq.com. 
defined as the time of dynamic adsorption breakthrough point $\left(t_{\mathrm{B}}, \min \right)$, the time when $c_{\text {eff }}=0.9 c_{\text {in }}$ was the saturation point $\left(t_{\mathrm{E}}, \mathrm{min}\right)$, and the dynamic saturated adsorption amount $\left(Q_{\mathrm{m}}, \mathrm{mg} / \mathrm{g}\right)$ was calculated by formula (1).

$$
Q_{\mathrm{m}}=\frac{\left(c_{\text {in }}-c_{\mathrm{o}}\right) \times q_{\text {in }} \times t_{\mathrm{E}}}{1000 \times m}
$$

In formula (1), $Q_{\mathrm{m}}$ is the static saturated adsorption amount $(\mathrm{mg} / \mathrm{g}), q_{\text {in }}$ is the flow rate of the raw material solution $(\mathrm{mL} / \mathrm{min})$, and $c_{0}$ is the concentration of the collected solution $(\mathrm{mg} / \mathrm{L})$ at the dynamic adsorption saturation point.

(2) Dynamic adsorption simulation

Thomas dynamic adsorption equation was selected to simulate the dynamic adsorption behavior of $\mathrm{MB}$ in GO/PAM medium. The specific mathematical expression of Thomas dynamic adsorption equation is shown in equation $(2)^{[8]}$.

$$
\frac{C_{\text {eff }}}{c_{\text {in }}}=1 /\left[1+\exp \left(\frac{K_{\mathrm{Th}} \cdot Q \cdot m}{q_{\text {in }}}-K_{\mathrm{Th}} \cdot c_{\text {in }} \cdot t\right)\right]
$$

In formula (2), $c_{\text {in }}$ is the initial concentration of $\mathrm{MB}$ $(\mathrm{mg} / \mathrm{L}), c_{\text {eff }}$ is the outflow concentration of MA $(\mathrm{mg} / \mathrm{mL})$, $K_{\text {th }}$ is the rate constant of Thomas equation $(\mathrm{mL} /(\mathrm{mg} \cdot \mathrm{min})), Q$ is the calculated adsorption amount $(\mathrm{mg} / \mathrm{g}), q_{\text {in }}$ is the feed flow rate $(\mathrm{mL} / \mathrm{min}), m$ is the mass of adsorption medium (g), and $t$ is the outflow concentration of $c_{\text {eff }}$ time ( $\left.\mathrm{min}\right)$.

Equation (2) is changed into:

$$
\begin{aligned}
& \frac{c_{\text {in }}}{c_{\text {eff }}}-1=\exp \left(\frac{K_{\mathrm{Th}} \cdot Q \cdot \mathrm{m}}{q_{\text {in }}}\right) \times \exp \left(-K_{\mathrm{Th}} \cdot c_{\text {in }} \cdot t\right) \\
& \text { Order: } \boldsymbol{Y}^{*}=\frac{c_{\text {in }}}{c_{\text {eff }}}-1 ; \quad \boldsymbol{A}=\exp \left(\frac{K_{\mathrm{Th}} \cdot Q \cdot m}{q_{\text {in }}}\right) ;
\end{aligned}
$$

$\boldsymbol{B}=K_{T h} \cdot c_{\text {in }}$

In equation (3), $\boldsymbol{Y}^{*}$ is the real measured value (dimension is 1).

Thomas equation is equivalent to:

$$
\boldsymbol{Y}=\boldsymbol{A} \times \exp (-\boldsymbol{B} \cdot t)
$$

In equation (4), $\boldsymbol{Y}$ is the calculated value of the model.

Taking the dynamic adsorption data under different operating conditions as the parameter estimation actual data, the parameter estimation of equation (4) was carried out to obtain the exponential equation fitting relationship between $\boldsymbol{Y}$ and dynamic adsorption time $t$ (min) under different operating conditions.

\section{Results and discussion}

\subsection{Dynamic adsorption behavior}

(1) Initial concentration of feed liquid

Under the same adsorption operation conditions, change the initial concentrations of MB dynamic adsorption feed liquid, and detect the dynamic adsorption breakthrough curves under different $\mathrm{MB}$ initial concentrations as shown in Fig.2. The breakthrough curves shift to the left with the increased of the initial concentration of MB. When the initial concentration of MB increased from $20 \mathrm{mg} / \mathrm{L}$ to $100 \mathrm{mg} / \mathrm{L}$, the breakthrough time was shortened from $220 \mathrm{~min}$ to $125 \mathrm{~min}$. It can be seen from table 1 that when the initial concentration of $\mathrm{MB}$ increased, the dynamic adsorption capacity of the medium for MB also increased.

(2) Different feed fluid flow

The breakthrough curves obtained by changing the feed flow rate at the same MB initial concentration were shown in Fig. 3. When the flow rate of MB increased from $2 \mathrm{~mL} / \mathrm{min}$ to $10 \mathrm{~mL} / \mathrm{min}$, the breakthrough curves shift to the left, and the breakthrough time is shortened from $217 \mathrm{~min}$ to $115 \mathrm{~min}$. From the data in Table 1, it can be seen that with the increase of feed liquid flow, the saturated adsorption capacity of GO/PAM medium on MB did not always increase. When the initial flow of feed liquid was more than $8 \mathrm{~mL} / \mathrm{min}$, the saturated adsorption capacity of medium decreased, mainly because the flow rate was too high, MB has not yet interacted with the adsorption sites in the medium, and the adsorption efficiency decreased.

(3) Adsorption temperature

Under the conditions of the same feed flow rate and initial MB concentration, change the ambient temperatures of medium adsorption to investigate the influence of adsorption temperatures on dynamic adsorption, as shown in Fig. 4. When the adsorption temperature raised from $278.15 \mathrm{~K}$ to $318.15 \mathrm{~K}$, the dynamic adsorption breakthrough time decreased from $197 \mathrm{~min}$ to $144 \mathrm{~min}$. From table 1, it can be seen that the adsorption capacity of the medium decreased with the increased of the adsorption temperature.

\subsection{Simulation results of dynamic adsorption}

Thomas equation was selected to simulate the dynamic adsorption processes of $\mathrm{MB}$ on GO/PAM medium. Formula (3) was used to compare the exponential fitting of dynamic adsorption processes under different operating conditions with the actual experimental measurement values as shown in Fig. 5, Fig. 6 and Fig. 7. The simulation calculation results of Thomas equation are shown in Table 1. From the results in Table 1, it can be seen that $\mathrm{R} 2=(0.9522 \sim 0.9866)$ of the fitting equations corresponding to different initial concentrations of $\mathrm{MB}$, $\mathrm{R} 2=(0.9608-0.9686)$ of the fitting equations corresponding to different feed flow rates, and R2= (0.9632-0.9794) of the fitting equations under different adsorption temperatures. The maximum relative deviation percentage of the adsorption capacity calculated by Thomas equation and the actual measured value was $<6 \%$. By comparing the calculated value with the measured values, Thomas equation can well simulate the dynamic adsorption behavior of $\mathrm{MB}$ in $\mathrm{GO} / \mathrm{PAM}$ structured medium, which could prove that Thomas equation could play a guiding role in the calculation of the adsorption capacity of MB in GO/PAM structured medium. 
Table. 1 The Thomas simulation results of MB dynamic adsorption in GO/PAM structured adsorption medium under different conditions.

\begin{tabular}{|c|c|c|c|c|c|c|c|c|}
\hline \multicolumn{2}{|c|}{ operation conditions } & $A(1)$ & $B\left(\min ^{-1}\right)$ & $K_{\mathrm{Th}}(\mathrm{mL} /(\mathrm{mg} \cdot \mathrm{min}))$ & $\begin{array}{c}\text { calculated } \\
Q(\mathrm{mg} / \mathrm{g})\end{array}$ & $\begin{array}{l}\text { measured } \\
Q_{m}(\mathrm{mg} / \mathrm{g})\end{array}$ & $s_{t} \%$ & $R^{2}$ value \\
\hline \multirow{5}{*}{$C_{\text {in }}(\mathrm{mg} / \mathrm{L})$} & 20 & $3.22 \mathrm{E}+05$ & 0.0473 & 2.364 & 64.38 & 64.64 & 5.81 & 0.9866 \\
\hline & 40 & $4.35 \mathrm{E}+05$ & 0.0544 & 1.361 & 114.49 & 112.74 & 1.53 & 0.9854 \\
\hline & 60 & $3.15 \mathrm{E}+06$ & 0.0715 & 1.192 & 150.64 & 151.45 & 0.54 & 0.9522 \\
\hline & 80 & $8.29 \mathrm{E}+06$ & 0.0876 & 1.095 & 174.54 & 178.65 & 2.35 & 0.9632 \\
\hline & 100 & $2.00 \mathrm{E}+06$ & 0.0975 & 0.975 & 178.62 & 181.27 & 1.48 & 0.9673 \\
\hline \multirow{5}{*}{$q_{\text {in }}(\mathrm{mL} / \mathrm{min})$} & 2 & $1.20 \mathrm{E}+09$ & 0.0881 & 1.101 & 75.93 & 71.47 & 5.87 & 0.9608 \\
\hline & 4 & $5.03 \mathrm{E}+08$ & 0.1002 & 1.253 & 127.97 & 126.38 & 1.24 & 0.9663 \\
\hline & 6 & $8.29 \mathrm{E}+06$ & 0.0876 & 1.095 & 174.54 & 178.65 & 2.35 & 0.9632 \\
\hline & 8 & $4.00 \mathrm{E}+06$ & 0.0952 & 1.189 & 204.50 & 201.58 & 1.43 & 0.9621 \\
\hline & 10 & $2.36 \mathrm{E}+06$ & 0.1160 & 1.451 & 202.40 & 196.87 & 2.73 & 0.9686 \\
\hline \multirow{5}{*}{$T(\mathrm{~K})$} & 278.15 & $8.44 \mathrm{E}+08$ & 0.0969 & 1.211 & 203.72 & 202.78 & 0.46 & 0.9664 \\
\hline & 288.15 & $1.06 \mathrm{E}+07$ & 0.0839 & 1.048 & 185.17 & 187.73 & 1.38 & 0.9659 \\
\hline & 298.15 & $8.29 \mathrm{E}+06$ & 0.0876 & 1.095 & 174.54 & 178.65 & 2.35 & 0.9632 \\
\hline & 308.15 & $5.98 \mathrm{E}+05$ & 0.0763 & 0.954 & 167.39 & 162.73 & 2.78 & 0.9726 \\
\hline & 318.15 & $2.05 \mathrm{E}+05$ & 0.0735 & 0.919 & 159.67 & 151.83 & 4.91 & 0.9794 \\
\hline
\end{tabular}

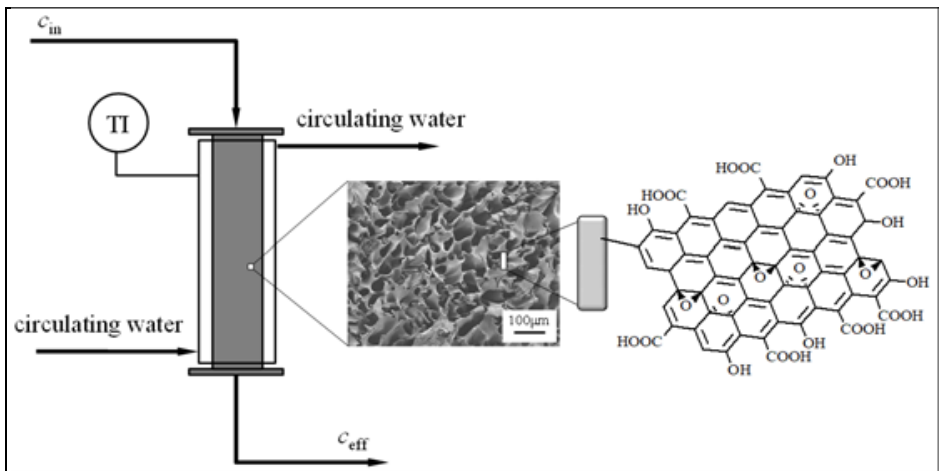

Fig. 1 Dynamic adsorption diagram of GO/PAM continuous adsorption medium.

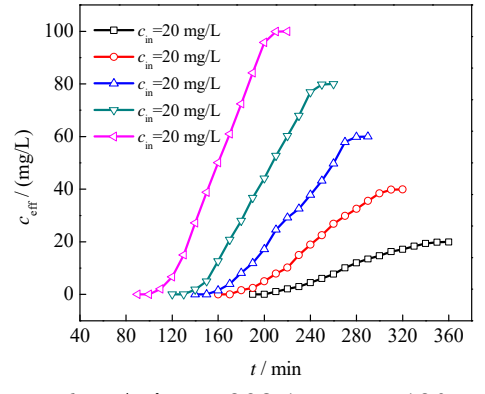

$q_{\text {in }}=6 \mathrm{~mL} / \mathrm{min}, T=298.15 \mathrm{~K}, \quad Z=120 \mathrm{~mm}$

Fig. 2 Breakthrough curves of different initial MB

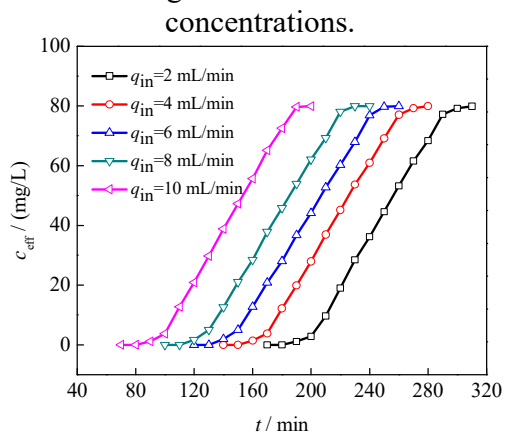

$C_{\text {in }}=80 \mathrm{mg} / \mathrm{L}, \quad T=298.15 \mathrm{~K}, \quad \mathrm{Z}=120 \mathrm{~mm}$

Fig. 3 Breakthrough curves under different feed flow rates.

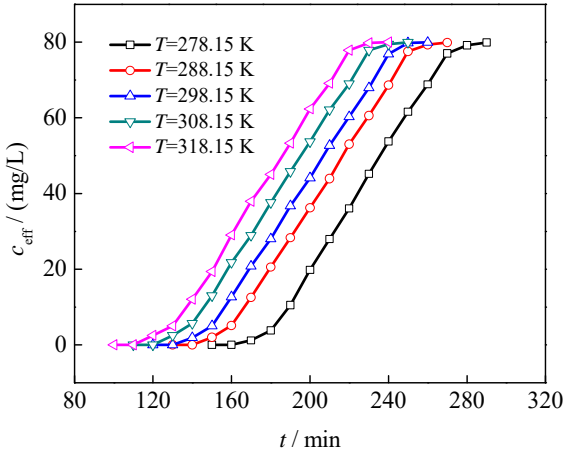

$C_{\text {in }}=80 \mathrm{mg} / \mathrm{L}, \quad q_{\text {in }}=6 \mathrm{~mL} / \mathrm{min}, \quad Z=120 \mathrm{~mm}$

Fig. 4 Breakthrough curves corresponding to different

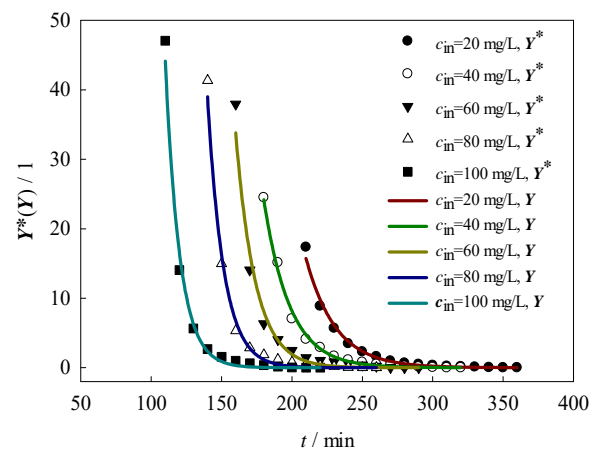

Fig. 5 The Thomas simulated and measured values of dynamic adsorption at different initial MB concentrations. 


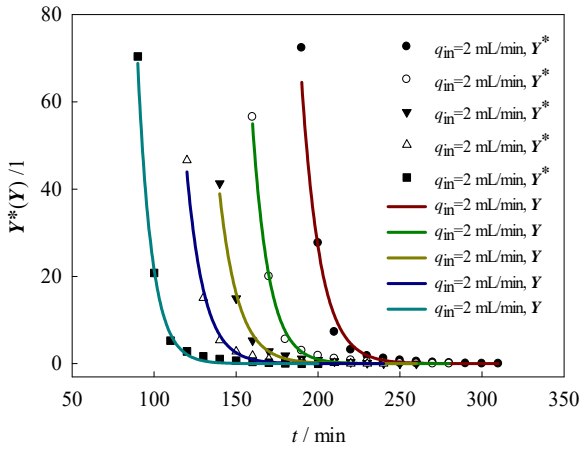

Fig. 6 The Thomas simulated and measured values of dynamic adsorption under different MB feed liquid flow rates.

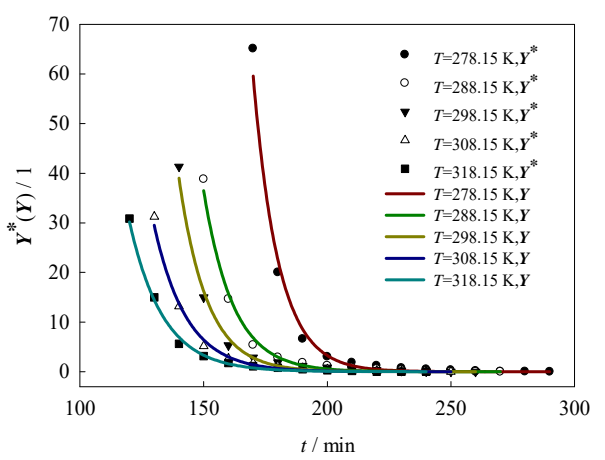

Fig. 7 The Thomas simulated and measured values of dynamic adsorption at different adsorption temperatures.

\section{Conclusion}

In this work, GO/PAM macroporous structured separation medium was successfully prepared, which realized the dynamic adsorption of $\mathrm{MB}$ at a high flow rate. The suitable flow rates of the adsorption solution were $6 \mathrm{~mL} / \mathrm{min} \sim 8 \mathrm{~mL} / \mathrm{min}$, the adsorption temperatures were $288.15 \mathrm{~K} \sim 298.15 \mathrm{~K}$, and the dynamic adsorption capacities were $178.65 \mathrm{mg} / \mathrm{g} \sim 201.58 \mathrm{mg} / \mathrm{g}$. With the increased of the initial concentration of $\mathrm{MB}$, the dynamic adsorption capacity increased. Thomas equation could well simulate the dynamic adsorption behavior of $\mathrm{MB}$ on GO/PAM structured adsorption medium, and the maximum relative deviation percentage between the calculated adsorption capacity and the actual adsorption capacity was less than $6 \%$, which played a guiding role in the study of dynamic adsorption characteristics of MB on the medium.

\section{Acknowledgments}

The authors gratefully acknowledge financial support from Special Program for Cultivating Outstanding Young Scientific Research Talents in Universities of Fujian Province (Grant No. JYTJQ20170605).

\section{References}

1. An A. K., Guo J., Jeong S. H., Lee E. J., Tabatabai S. A. A., Leiknes, T. (2016) High flux and antifouling properties of negatively charged membrane for dyeing wastewater treatment by membrane distillation. Water Research, 103: 362371.

2. Xiao J. M. (2017) Crack the printing and dyeing wastewater treatment wisdom, lead the textile industry green moving future. Textile Auxiliaries, 34: 6-12.

3. Song W., Gao B. Y., Xu X. (2016) Adsorptiondesorption behavior of magnetic amine $/ \mathrm{Fe}_{3} \mathrm{O}_{4}$ functionalized biopolymer resin towards anionic dyes from wastewater. Bioresource Technology, 210: 123-130.

4. Hubicki Z., Wawrzkiewicz M. (2016) Anion exchange resins of Tri-n-butyl Ammonium functional groups for dye baths and textile wastewater treatment. Solvent Extraction and Ion Exchange, 34: 558-575.

5. Li T., Zhou C. X. Y., Xie T. H., Liu W. B. (2015) Preparation of four tentacle-type strong base anion exchange resins and study on their adsorption properties for Eosin Y removal. Chemical Industry \& Engineering Progress, 34: 1377-1383,1388.

6. Kamal T., Anwar Y., Khanab S. B. (2016) Dye adsorption and bactericidal properties of TiO2/chitosan coating layer. Carbohydrate Polymers, 148: 153-160.

7. Li C., Zhang M., Song C. W (2018) Enhanced treatment ability of membrane technology by integrating an electric field for dye wastewater treatment: A Review. Journal of AOAC International, 101:1341-1352.

8. Thomas H. C. (1944) Heterogeneous ion exchange in a flowing system. Journal of the American Chemical Society, 66: 1664-1666. 